\title{
Effect of upper extremity proprioceptive neuromuscular facilitation combined with elastic resistance bands on respiratory muscle strength: a randomized controlled trial
}

\author{
Guilherme P. T. Areas ${ }^{1}$, Audrey Borghi-Silva ${ }^{2}$, Arianne N. Lobato ${ }^{3}$, \\ Alessandra A. Silva ${ }^{3}$, Renato C. Freire Jr' ${ }^{3}$, Fernando Z. S. Areas ${ }^{3}$
}

\begin{abstract}
Background: Elastic resistance bands (ERB) combined with proprioceptive neuromuscular facilitation (PNF) are often used in resistance muscle training programs, which have potential effects on peripheral muscle strength. However, the effects of the combination of ERB and PNF on respiratory muscle strength warrant further investigation. Objectives: The assessment of the effects of PNF combined with ERB on respiratory muscle strength. Method: Twenty healthy, right-handed females were included. Subjects were randomized to either the resistance training program group (TG, $n=10)$ or the control group $(\mathrm{CG}, \mathrm{n}=10)$. Maximal expiratory pressure (MEP) and inspiratory pressure (MIP) were measured before and after four weeks of an upper extremity resistance training program. The training protocol consisted of upper extremity PNF combined with ERB, with resistance selected from 1 repetition maximum protocol. Results: PNF combined with ERB showed significant increases in MIP and MEP $(p<0.05)$. In addition, there were significant differences between the TG and CG regarding $\triangle \mathrm{MIP}(\mathrm{p}=0.01)$ and $\triangle \mathrm{MEP}(p=0.04)$. Conclusions: PNF combined with ERB can have a positive impact on respiratory muscle strength. These results may be useful with respect to cardiopulmonary chronic diseases that are associated with reduced respiratory muscle strength.
\end{abstract}

Keywords: elastic band; PNF; resistance exercise; respiratory muscle; strength; physical therapy. Clinical Trial (Registro Brasileiro de Ensaios Clínicos): RBR-3SS6ZT.

\section{HOW TO CITE THIS ARTICLE}

Areas GPT, Borghi-Silva A, Lobato AN, Silva AA, Freire Jr RC, Areas FZS. Effect of upper extremity proprioceptive neuromuscular facilitation combined with elastic resistance bands on respiratory muscle strength: a randomized controlled trial. Braz J Phys Ther. 2013 Nov-Dec; 17(6):541-546. http://dx.doi.org/10.1590/S1413-35552012005000131

\section{Introduction}

Resistance exercise training produces several changes in muscle, such as hypertrophy, increased oxidative capacity, and changes in muscle fiber type ${ }^{1,2}$. These physiological adaptations are accomplished to increase muscle force, endurance, and functional exercise capacity, which are reflected in improved quality of life and independence in activities of daily living. Therefore, several applications of this type of training exist in various areas of rehabilitation, including the orthopedic and cardiorespiratory fields ${ }^{3,4}$.

Currently, specific respiratory muscle training, which applies linear resistance pressures during spontaneous breathing, has had significant effects on respiratory muscle strength and endurance . $^{5}$ Conversely, upper extremity resistance exercises may improve respiratory muscle strength. The literature has indicated that the increase in respiratory muscle strength may improve the physical capacity of various populations, such as healthy athletes ${ }^{6}$ or patients with heart and lung disease ${ }^{6-8}$.

In this context, Moreno et al. ${ }^{9}$ demonstrated that the use of upper limb resistance exercise is effective in increasing both inspiratory and expiratory muscle strength. In Moreno's et al. ${ }^{9}$ study, proprioceptive neuromuscular facilitation (PNF), combined with pulleys, was the exercise chosen to treat the upper limb. PNF is an approach to exercise therapy that uses specific movement patterns in diagonal and spiral directions together with specific techniques that facilitate the increase in strength and muscle function ${ }^{10}$. The findings of Moreno et al. ${ }^{9}$ regarding the improvement of respiratory muscle function confirm the results of Voss et al. ${ }^{10}$, which reported that PNF could be applied in a pulmonary rehabilitation program because it acts on trunk and neck muscles that are closely linked to respiratory function. 
The combination of PNF with pulleys was beneficial in training with gains in respiratory muscle strength ${ }^{9}$. However, recent studies have shown that elastic bands can be used more effectively compared with other devices, such as free weights and machines associated with unidirectional movements ${ }^{11,12}$. Elastic resistance bands (ERB) have been widely used in clinical practice because they are easy to use, inexpensive, do not require physical space and, unlike free weights, do not rely on gravity to provide resistance ${ }^{13-15}$.

Elastic resistance training with bands has been shown to increase mobility and balance and to improve muscle strength ${ }^{16-18}$. To the best of our knowledge, however, no study has investigated whether PNF combined with elastic ERB can improve respiratory muscle strength. Thus, the aim of the present study was to verify whether a 4-week training program consisting of upper extremity PNF combined with ERB would increase respiratory muscle strength.

\section{Method}

\section{Participants}

The participants were invited to join the study through public advertisments at our institution. The inclusion criteria were: normotension ${ }^{19}$, age between 18 to 25 years old, right-handedness according to the Edinburgh Handedness Inventory ${ }^{20}$, and sedentary classification in the International Physical Activity Questionnaire (IPAQ) ${ }^{21}$. We excluded participants with orthopedic or neurological conditions that would preclude participation in the exercise program; participants who were unable to perform $100 \%$ of 1-RM with the elastic bands used in the study or who failed to comply with the research protocol; and those with a history of cardiac arrhythmia, heart disease, controlled or uncontrolled hypertension, diabetes mellitus or other respiratory diseases. We also excluded underweight or obese patients who smoked or had hormonal disorders, pregnant women, and those who used substances that affected cardiovascular response.

A prospective randomized trial was carried out with 20 healthy, young, right-handed females who were randomized to either the training group (TG, $\mathrm{n}=10$ ) or the control group (CG, $\mathrm{n}=10$ ) by drawing shuffled, opaque, coded envelopes that were opened immediately before the start of first session for each participant. The study protocol was approved by the Ethics Committee of Universidade Federal do
Amazonas (UFAM), Manaus, AM, Brazil (approval no. 070/2011), and all participants signed a consent form before the initial testing session.

\section{Selection of elastic bands}

The 1-RM test with the elastic resistance load was carried out with the participant sitting parallel to the side of the wooden apparatus on a chair with a backrest. The wooden apparatus is $230 \mathrm{~cm}$ tall with 11 steps, and the elastic band was positioned on the second to last step. All of the bands were $200 \mathrm{~cm}$ long, attached to a cuff, and tied according to manufacturer instructions ${ }^{13}$. The cuff was then placed on the participant's wrist, leaving a free hand to ensure that the standard PNF was performed correctly.

The elastic bands (Thera-Band ${ }^{\circledR}$, Hygenic Corporation, Akron, OH, USA) used in this study were red, blue, green, and black. The introduction of these bands was based on studies by Santos et al. ${ }^{22}$, which demonstrated that there is a difference in resistance of 15 to $25 \%$ among the bands. Each individual began the 1-RM test with the lowest elastic load (red color) and increased to the elastic load that prevented the performance of the movement. Furthermore, due to the difficulty of imposing a fixed load, a lighter resistance band was used for training, with approximate values between 71 and $86 \%$ of $1-\mathrm{RM}$.

To describe the load and percentage of elongation in the use of the elastic band, the values described in the Thera-Band ${ }^{\circledR 12}$ website were used. The calculation of the percentage of elongation was as follows: \% elongation $=[($ final length - initial length $) /$ (initial length) $] \times 100$. Elongation percentage was obtained through the values at each load produced in a specific color range ${ }^{13}$.

\section{Experimental procedure}

The movement followed the basic procedures used in the PNF concept. The pattern used in the present study was flexion - abduction - external rotation with the elbow extended and extension - adduction - internal rotation with the elbow extended, using the reversal of antagonists as a specific technique ${ }^{10}$. The training protocol consisted of three sets of ten repetitions, with a 60 -second rest interval between sets. The training protocol consisted of three sessions per week for 4 weeks. Sessions were held in the late afternoon and in the early evening. The CG did not perform any activity during the experimental procedure and was re-evaluated after 4 weeks. 


\section{Measurements of respiratory pressures}

Maximum expiratory pressure (MEP) and maximum inspiratory pressure (MIP) were measured using a digital manometer (MVD-300 ${ }^{\circledR}$, Globalmed, Porto Alegre, RS, Brazil). A rubber mouthpiece with an internal diameter of $32 \mathrm{~mm}$ was connected to a plastic tube with a 2-mm diameter leak to avoid any elevation of pressure within the oral cavity by contraction of the facial muscles ${ }^{23}$. This plastic tube was coupled with a $30-\mathrm{cm}$ trachea, measuring $30 \mathrm{~mm}$ in diameter and attached to the vacuum manometer according to manufacturer specifications.

First, the subjects were instructed to remain in a seated position. A demonstration of how the maneuvers should be carried out was given and then performed by the subject after the placement of a nose clip. The subjects were instructed to keep their lips sealed tightly around the mouthpiece so no air could escape. MIP values were obtained by inspiration from residual volume $(\mathrm{RV})^{24}$, which was repeated at least three times with a one-minute interval between repetitions. MEP was then obtained by expiration from total lung capacity (TLC), using the same methodology applied in inspiration. During the MIP maneuver, the subject kept the mouthpiece in the oral cavity only during the inspiration, and in the MEP maneuver, only during expiration. The maneuvers were sustained at maximal force for approximately one second and the highest value was computed from a minimum of three repetitions for each maneuver with a maximum difference of $10 \%$ between values ${ }^{25}$.

\section{Statistical analysis}

The Shapiro-Wilk test was applied to verify the distribution of the data. For parametric paired data, Student's $t$ test was used. For non-parametric data, the Mann-Whitney U test was used with the level of significance set at $p<0.05$, effect sizes $=1.5, \alpha=0.05$, sample size $=9$, and $\beta=0.82$. The effect sizes for each mean difference were calculated using Cohen's d. The statistical programs used were GraphPad Prism ${ }^{\circledR}$ version 5.0 (GraphPad Software Inc., San Diego, CA, USA) and G*Power 3.1 (Christian-AlbrechtsUniversität, Kiel, Germany).

\section{Results}

Initially, 20 participants were evaluated (10 in the $\mathrm{CG}$ and 10 in the TG). Five participants were excluded from the CG (three dropped out and two started physical activity), and two dropped out of the TG. In the end, 5 participants remained in the CG and 8 in the TG. Values are expressed as mean \pm SE.
The anthropometric and hemodynamic values are shown in Table 1.

Table 2 shows the characteristics of each participant in the TG during the study, such as the color of the band, \% elongation in the range of exercise performance, and the load used by the individuals. The results of respiratory muscle pressures before and after 4 weeks of TG and CG are shown in Table 3. There was no difference between the CG and the TG before the beginning of training. When comparing the beginning and the end of the study after 4 weeks of training, a significant difference was observed in the $\mathrm{TG}$ at the end of the experiment in relation to both the MIP (72.4 \pm 7.2 to $\left.124.6 \pm 21.6 \mathrm{cmH}_{2} \mathrm{O} ; p<0.05\right)$ and $\%$ predicted $(-4.0 \pm 2.5$ to $45 \pm 16.5 ; p=0.001)$ and the MEP $\left(71.0 \pm 6.4\right.$ to $\left.92.2 \pm 5.6 \mathrm{cmH}_{2} \mathrm{O} ; p<0.05\right)$ and $\%$ predicted $(0.16 \pm 4.3$ to $29.3 \pm 10.2 ; p=0.01)$. In addition, the CG showed no increase in MIP and

Table 1. Anthropometric and hemodynamic data for the control group (CG) and the treated group (TG). Data are expressed as mean \pm SE.

\begin{tabular}{lccc}
\hline & CG $(\mathbf{n = 0 5})$ & TG $(\mathbf{n = 0 8})$ & $p$ \\
Age (years) & $21 \pm 0.8$ & $20 \pm 2.0$ & 0.272 \\
Weight $(\mathrm{Kg})$ & $49.7 \pm 2.1$ & $50.7 \pm 2.9$ & 0.305 \\
Height (meters) & $1.5 \pm 0.06$ & $1.5 \pm 0.06$ & 0.305 \\
BMI (Kg/m $\left.{ }^{2}\right)$ & $21.1 \pm 0.7$ & $21.7 \pm 1.8$ & 0.187 \\
MIP & $87.6 \pm 10.2$ & $72.3 \pm 17.7$ & 0.091 \\
MIP (\% predicted) & $83 \pm 12$ & $71 \pm 20$ & 0.070 \\
MEP & $74.2 \pm 13.96$ & $71.0 \pm 6.4$ & 0.124 \\
MEP (\% Predicted) & $70 \pm 20$ & $68 \pm 15$ & 0.280 \\
Approximate Load $(\mathrm{Kg})$ & - & $2.9 \pm 0.8$ & - \\
\hline
\end{tabular}

$\mathrm{BMI}=$ Body mass index $\left(\mathrm{Kg} / \mathrm{m}^{2}\right)$.

Table 2. Absolute values of the characteristics of the approximate load, the type of elastic band, and \% Elongation of the elastic band of the TG $(n=08)$.

\begin{tabular}{ccccc}
\hline Individual & $\begin{array}{c}\% \\
\text { RM* }\end{array}$ & $\begin{array}{c}\text { Color of } \\
\text { elastic }\end{array}$ & $\begin{array}{c}\% \\
\text { Elongation }\end{array}$ & $\begin{array}{c}\text { Approximate } \\
\text { Load(Kg)* }\end{array}$ \\
01 & $71 \%$ & Green & $105 \%$ & 2.3 \\
02 & $71 \%$ & Green & $112 \%$ & 2.6 \\
03 & $71 \%$ & Green & $115 \%$ & 2.6 \\
04 & $71 \%$ & Green & $109 \%$ & 2.3 \\
05 & $73 \%$ & Blue & $112 \%$ & 3.7 \\
06 & $86 \%$ & Red & $121 \%$ & 2.0 \\
07 & $73 \%$ & Blue & $138 \%$ & 4.0 \\
08 & $73 \%$ & Blue & $137 \%$ & 4.0 \\
\hline
\end{tabular}

*Page et al. ${ }^{13}$. 
A

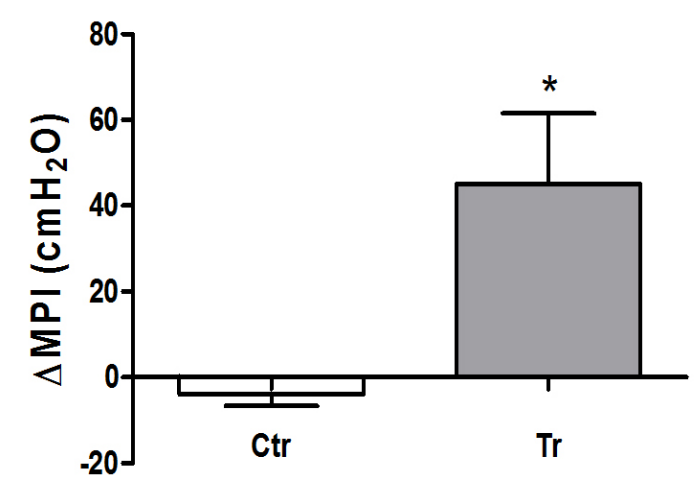

B

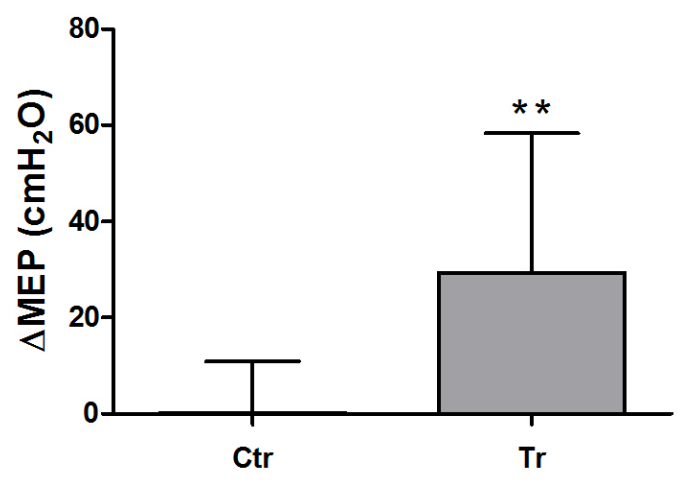

Figure 1. A) Values of $\Delta$ MIP. B) $\Delta$ MEP for the $\mathrm{CG}(\mathrm{n}=05)$ and the TG $(\mathrm{n}=08)$. Data are expressed as mean $\pm \mathrm{SE} .{ }^{*} p=0.01 / \mathrm{effects}$ size $=1.22 ; * *=0.04 /$ effects size $=1.61$.

Table 3. Values of MIP and MEP for the CG $(n=05)$ and the TG $(n=08)$. Data are expressed as mean \pm SE.

\begin{tabular}{lcccc}
\hline & $\begin{array}{c}\text { Initial } \\
\text { CG }\end{array}$ & $\begin{array}{c}\text { Final } \\
\text { CG }\end{array}$ & $\begin{array}{c}\text { Initial } \\
\text { TG }\end{array}$ & Final TG \\
MIP & $87.6 \pm 10.2$ & $80.2 \pm 7.9$ & $72.3 \pm 17.7$ & $124.6 \pm 21.5^{*}$ \\
MIP & $83 \pm 12$ & $81 \pm 08$ & $71 \pm 20$ & $118 \pm 3^{* *}$ \\
$(\%$ predicted) & & & & \\
MEP & $74.2 \pm 13.9$ & $80.6 \pm 14.4$ & $71.0 \pm 6.4$ & $92.2 \pm 5.6^{\#}$ \\
MEP & $70 \pm 20$ & $76 \pm 13$ & $68 \pm 15$ & $89 \pm 21^{\S}$ \\
(\% predicted) & & & & \\
\hline
\end{tabular}

$\mathrm{MIP}=$ maximum inspiratory pressure $\left(\mathrm{cmH}_{2} \mathrm{O}\right)$; $\mathrm{MEP}=$ maximum expiratory pressure $\left(\mathrm{cmH}_{2} \mathrm{O}\right)$; Initial vs. Final in Treated group - $* p<0.05 /$ effects size $=1.74 ; * * p=0.001 /$ effects size $=1.56$; ${ }^{\#} p<0.05 /$ effects size $=1.05 ;{ }^{\circledR} p=0.01 /$ effects size $=0.70$.

$\%$ predicted $(p>0.05 /$ effect sizes $=0.49$ and 0.1 , respectively) or MEP and \% predicted ( $p>0.05 /$ effect sizes $=0.32$ and 0.30 , respectively).

Figures $1 \mathrm{~A}$ and $\mathrm{B}$ show the differences between the $\mathrm{CG}$ and the TG in the $\triangle \mathrm{MIP}$ values and $\triangle \mathrm{MEP}$ values, respectively. In the $\triangle \mathrm{MIP}$ values, the difference was: $\mathrm{CG}=-4.0 \pm 2.5 ; \mathrm{TG}=45.0 \pm 16.5(p=0.01)$; and in the $\triangle \mathrm{MEP}$ values, the difference was: $\mathrm{CG}=0.16 \pm 4.0$; $\mathrm{TG}=29.3 \pm 10.2(p=0.04)$.

\section{Discussion}

The most important findings obtained in this study were the significant increases in both MIP and MEP after one month of training with PNF combined with elastic bands. As far as we know, this is the first study to contrast the effects of elastic bands combined with PNF specifically in the outcomes of respiratory muscle strength. Respiratory muscle dysfunction is a common disorder that may occur in respiratory and cardiovascular diseases ${ }^{26}$. In addition, it has been described that inspiratory muscle strength is reduced in chronic heart failure and emerges as a new, independent predictor of prognosis in these patients ${ }^{26}$. Moreover, the aging process has a negative impact on respiratory muscle strength, thus programs can be adopted in these patients and may have clinical relevance ${ }^{27}$.

When we compared our data with those obtained in the study by Moreno et al. ${ }^{9}$, which evaluated the effects of PNF alone on the respiratory muscle force of 7 healthy subjects, we noted that the increase in inspiratory and expiratory muscle strength had a very similar magnitude with similar sample sizes. In addition, in a different protocol, Colado et al. ${ }^{12}$ compared the gains in upper limb muscle activity and strength through exercises using free weights and resistance machines with elastic bands. These researchers found similar results to those of the present study. Additionally, Witt et al. ${ }^{28}$ studied electromyographic activity in the scapular muscle during various PNF pattern movements combined with free weights and elastic resistance. In that study ${ }^{12}$, no difference was observed in either type of resistance.

Although it was not the objective of the present study, we can assume that the increases in respiratory muscle strength were similar when using elastic bands and free weights; however, further studies are required to identify this assumption. Conversely, it is known that physical training exerts different effects on muscle strength, especially in muscle resistance training ${ }^{1}$. However, previous studies have shown that PNF produces changes in muscle fiber types, 
specifically changing fiber type IIA to IIB, and reduces the cross-sectional area of type IIB fibers ${ }^{2}$. In addition, Hostler et al. ${ }^{29}$ reported that the use of elastic bands changed muscle fiber type IIB to IIAB and increased capillary blood flow after 8 weeks of training with low-load, high-repetition lower limb exercise.

Based on these studies, it can be inferred that the beneficial physiological muscle response of increase in respiratory muscle strength is related to changes in muscle fiber type associated with two muscle resistance training techniques. However, future research in this area is needed to address these issues and more firmly establish the relationship between the changes in the type of muscle fibers of respiratory muscles and the combination of PNF and ERB training.

Even considering the increase in respiratory muscle strength and the possibility of changes in muscles after training, there is still no evidence regarding which muscles are related to the effects observed in the study. Moreno et al. ${ }^{9}$ reported that PNF possibly stimulates the main respiratory muscles (diaphragm and intercostals), as well as other accessory muscles (neck muscles, chest wall, and upper limbs). Although the pattern used in the current study did not directly influence the muscles mentioned above, it is known that PNF operates indirectly from the main muscles trained ${ }^{10}$. In addition, Sullivan and Portney ${ }^{30}$ studied the electromyographic activity of various upper limb PNF patterns and described that the same pattern used in this study activates the muscles of the pectoralis major and serratus anterior, both accessory respiratory muscles, and may possibly have an effect on the increase in respiratory muscle activity.

Morales et al. ${ }^{31}$ also used electromyography to study upper limb muscle irradiation after using PNF and found increased electrical activity of the contralateral muscles exercised. This experiment can provide the scientific basis of the possible effect related to the irradiation not only in the muscles of the neck and chest of the same side that the individual trained but also of the bilateral activation of the anatomical structures. We can assume that the gain produced by the respiratory function may be due to the increased bilateral activity of the respiratory muscles.

Both the effect of increase in muscle strength and the possible effect of change in the type of muscle fibers are important for the treatment of various diseases. Currently, it is known that various respiratory diseases produce changes in both respiratory function and respiratory muscle function ${ }^{7-9}$ and that the use of neuromuscular facilitation for the treatment of disorders combined with elastic bands would help the treatment of these patients, as it is of great importance in clinical practice due to the ease of use of these modalities in physical rehabilitation.

ERB are inexpensive, require no complicated installation, and can be used both at home and in the clinical environment, in contrast to pulleys as proposed by Voss et al. ${ }^{10}$ and Moreno et al. ${ }^{9}$. However, future studies should focus on the comparison between PNF combined with pulleys and PNF combined with elastic bands in the clinical improvement of respiratory disorders.

\section{Conclusions}

Resistance exercise using ERB combined with PNF may be an option for rehabilitation in respiratory mechanics, specifically in the maximal inspiratory and expiratory pressures in subjects who underwent this intervention. However, there is a need for further studies to describe the use of these devices in respiratory disorders as the present research was conducted in healthy subjects.

\section{Acknowledgements}

The Beatriz Ribeiro Ferreira Pucci, for her help in proofreading the English text.

\section{References}

1. Williams MA, Haskell WL, Ades PA, Amsterdam EA, Bittner V, Franklin BA, et al. Resistance exercise in individuals with and without cardiovascular disease: 2007 update. Circulation. 2007;116(5):57284. PMid:17638929. http://dx.doi.org/10.1161/ CIRCULATIONAHA.107.185214

2. Kofotolis N, Vrabas IS, Vamvakoudis E, Papanikolaou A, Mandroukas K. Proprioceptive neuromusclar facilitation training induced alterations in muscle fibre type and cross sectional area. Br J Sports Med. 2005;39(3):1-4. PMid:15728679 PMCid:PMC1725148. http://dx.doi. org/10.1136/bjsm.2004.010124

3. Bennell KL, Hinman RS. A review of the clinical evidence for exercise in osteoarthritis of the hip and knee. J Sci Med Sport. 2011;14(1):4-9. PMid:20851051. http://dx.doi. org/10.1016/j.jsams.2010.08.002

4. Braith RW, Beck DT. Resistance exercise: training adaptations and developing a safe exercise prescription. Heart Fail Rev. 2008;13(1):69-79. PMid:17932746. http:// dx.doi.org/10.1007/s10741-007-9055-9

5. Hajghanbari B, Yamabayashi C, Buna T, Coelho JD, Freedman K, Morton TA, et al. Effects of respiratory muscle training on performance in athletes: a systematic review with meta-analyses. J Strength Cond Res. 2013;27(6):1643-63. PMID: 22836606. http://dx.doi. org/10.1519/JSC.0b013e318269f73f 
6. Kilding AE, Brown S, McConnell AK. Inspiratory muscle training improves 100 and $200 \mathrm{~m}$ swimming performance. Eur J Appl Physiol. 2010;108(3):505-11. PMid:19841931. http://dx.doi.org/10.1007/s00421-009-1228-x

7. Ramires-Sarmiento A, Orozco-Levi M, Guell R, Barreiro E, Hernandez N, Mota S, et al. Inspiratory muscle training in patients with chronic obstructive pulmonary disease: structural adaptation and physiologic outcomes. Am J Respir Crit Care Med. 2002;166(11):14917. PMid:12406842. http://dx.doi.org/10.1164/ rccm.200202-075OC

8. Gosselink R, De Vos J, Van den Heuvel SP, Segers J, Decramer M, Kwakkel G. Impact of inspiratory muscle training in patients with COPD: what is the evidence? Eur Respir J. 2011;37(2):416-25. PMid:21282809. http:// dx.doi.org/10.1183/09031936.00031810

9. Moreno MA, Silva E, Gonçalves M. O efeito das técnicas de facilitação neuromuscular proprioceptivo-método Kabat- nas pressões respiratórias máximas. Fisioter Mov. 2005;18(2):53-61.

10. Voss DE, Ionta MK, Myers B. Facilitação neuromuscular proprioceptiva. São Paulo: Médica Panamericana; 1987.

11. Hughes CJ, Hurd K, Jones A, Sprigles S. Resistance properties of thera-band tubing during shoulder abduction exercise. J Orthop Sports Phys Ther. 1999;29(7):41320. PMid:10416181. http://dx.doi.org/10.2519/ jospt.1999.29.7.413

12. Colado JC, Garcia-Masso X, Pellicer M, Alakhdar Y, Benavent J, Cabeza-Ruizar R. A comparison of Elastic Tubing and Isotonic Resistance Exercises. Inter J Sports Med. 2010;31(11):810-7. PMid:20703977. http://dx.doi. org/10.1055/s-0030-1262808

13. Page P, Labbe A, Topp RV. Clinical force production of Thera-band elastic bands. J Orthop Sports Phys Ther. 2000;A30:47-48.

14. Thera-Band Instruction. Resistance elastic and tubing. 4. 2003 - [cited 2010 Nov 19]. Available from: http://www. thera-band.com.

15. Simoneau GG, Bereda SM, Sobush DC, Starsky AJ. Biomechanics of elastic resistance in therapeutic exercise programs. J Orthop Sports Phys Ther. 2001(1)31:1624. PMid:11204792. http://dx.doi.org/10.2519/ jospt.2001.31.1.16

16. Losses JF, Kaetz AP, Soares DP, Scarrone FF, Henneman V, Sacharuk VZ. Quantificação da resistência oferecida por bandas elásticas. Rev Bras Ciênc Esporte. 2002;24(1):61-72.

17. Patil P, Rao S. Effects of Thera-Band ${ }^{\circledR}$ elastic resistanceassisted gait training in stroke patients: a pilot study. Eur J Phys Rehabil Med. 2011;47(3):427-33. PMid:21555984.

18. Veneri D. Combining the treatment modalities of body weight support treadmill training and Thera-Band: a case study of an individual with hemiparetic gait. Top Stroke Rehabil. 2011;18(4):402-16. PMid:21914606. http:// dx.doi.org/10.1310/tsr1804-402

19. Sociedade Brasileira de Cardiologia; Sociedade Brasileira de Hipertensão; Sociedade Brasileira de Nefrologia. VI Diretrizes Brasileiras de Hipertensão. Arq Bras Cardiol. 2010;95(suppl. 1): 1-51.
20. Oldfield RC. The assessment and analysis of handedness: the Edinburgh Inventory. Neuropsychology. 1971;9(1):97113. http://dx.doi.org/10.1016/0028-3932(71)90067-4

21. Barros MVG, Nahas MV, Markus VG. Reprodutibilidade (tesye-reteste) do questionário internacional de atividade física (QIAF-Versão 6): um estudo piloto com adultos no Brasil. Rev Bras Ciênc Mov. 2000;8(1):23-26.

22. Santos GM, Tavares GMS, Gasperi G, Bau G. Avaliação da resistência de faixas elásticas. Rev Bras Fisioter. 2009;13(6): 521-6. http://dx.doi.org/10.1590/ S1413-35552009000600009

23. Black LF, Hyatt RE. Maximal respiratory pressures: normal values and relationship to age and sex. Am Rev Respir Dis. 1969;99(5):696-702. PMid:5772056.

24. American Thoracic Society; European Respiratory Society. ATS/ERS statement on respiratory muscle testing. Am J Respir Crit Care Med. 2002;166(4):518624. PMid:12186831. http://dx.doi.org/10.1164/ rccm.166.4.518

25. Neder JA, Andreoni S, Lerario MC, Nery LE. Reference values for lung function tests. II. Maximal respiratory pressures and voluntary ventilation. Braz J Med Biol Res. 1999;32(6):719-27. PMid:10412550.

26. Meyer FJ, Borst MM, Zugck C, Kirschke A, Schellberg D, Kübler W, et al. Respiratory muscle dysfunction in congestive heart failure: clinical correlation and prognostic significance. Circulation. 2001;103(17):2153-8. http:// dx.doi.org/10.1161/01.CIR.103.17.2153

27. Simões RP, Deus AP, Auad MA, Dionízio J, Mazzonetto M, Borghi-Silva A. Maximal respiratory pressure in healthy 20 to 89 year-old sedentary individuals of central São Paulo State. Rev Bras Fisioter. 2010;14(1):60-7. http:// dx.doi.org/10.1590/S1413-35552010000100010

28. Witt D, Talbott N, Kotowski S. Electromyography activity of scapular muscle during diagonal patterns using elastic resistance and free weights. Int J Sports Phys Ther. 2011;6(4):322-32.

29. Hostler D, Schwirian CI, Campos G, Toma K, Crill MT, Hagerman GR, et al. Skeletal muscle adaptations in elastic resistance-trained young men and women. Eur J Appl Physiol. 2001;86(2):112-8. http://dx.doi.org/10.1007/ s004210100495

30. Sullivan PE, Portney LG. Electromyographic Activity of Shoulder Muscles During Unilateral Upper Extremity Proprioceptive Neuromuscular Facilitation Patterns. Phys Ther. 1980;60(30):283-8.

31. Morales MB, Carvalho GA, Gomes EB. Análise eletromiográfica dos efeitos contralaterais da facilitação neuromuscular proprioceptiva. Fisioter Bras. 2003;4(6):417-21.

\section{Correspondence}

\section{Guilherme Peixoto Tinoco Arêas}

Universidade Federal do Amazonas

Departamento de Ciências Fisiológicas - ICB

Av. General Rodrigo Otávio Jordão, 3000, Coroado

Setor Sul, Campus Universitário, Manaus, AM, Brasil

e-mail: guilhermepta@ufam.edu.br 